\title{
From Observing to Imagining the Opportunity of Freehand Drawing in Digital Era
}

\author{
Hanif Budiman \\ Faculty of Architecture And Design \\ Fatih Sultan Mehmet Vakif University, \\ Istanbul, Turkey \\ habudiman@uii.ac.id
}

\author{
Ibrahim Numan \\ Faculty of Architecture And Design \\ Fatih Sultan Mehmet Vakif University, \\ Istanbul, Turkey \\ inuman@fsm.edu.tr
}

\author{
Noor Cholis Idham \\ Architecture Departmen \\ Universitas Islam Indonesia, \\ Yogyakarta Indonesia \\ noor.idham@uii.ac.id
}

\begin{abstract}
When we lose the ability to draw, we lose a part of our ability to think [7]. Based on this thinking, practicing freehand drawing is still the best way to maintain the mind, the eyes, and the hands in balanced working coordination, as basic thinking tools of architects in term of the design process. Generally, drawing can be divided into two types, observation drawing, and imagination drawing. As part of science, especially for an architect, it is believed that observation activity by freehand drawing is proven as an effort that would increase awareness of a countless number of things among the brewing phenomenon in this complex and complicated of world development today, including digital development in the design process. Furthermore, in term of drawing as a way to emergence the imagination thinking, very important to understand that freehand drawing was performed a central function in the creative process, even a speculative idea. The aims of this paper are to discuss how the role of freehand drawing in improving the quality of thinking in term of the design process, as well as providing ideas for the emergence of critical and effective awareness by observation drawing activities and appropriate images by imagination drawing, in the midst of the development of today's digital era. The discussion was conducted through qualitative descriptive analysis based on experience carrying out freehand drawing courses and some freehand drawing activities. The topic about the role of drawing in the digital era is very strategic because it will remind us of the importance of the role of balance cognition for the general design process.
\end{abstract}

\section{Keywords: observation, imagination, cognition, design process}

\section{INTRODUCTION}

\section{A. Background}

The architectural theoretician Marco Frascari suggest that drawing can guide architects to an understanding of architecture as both constructed and construed because drawings intrinsically convey theory: "Real architecture drawings are not illustrations, but a pure expression of architectural thinking'. In the world of architecture, graphic images will always be present in various forms and were used to construct design ideas and will be interpreted by others. The best way to think graphically, to produce an architectural design process, is to carry out activities that activate all elements of cognition, such as thinking, seeing, recording, feeling, as well as imaginative thinking. The best activity for this is drawing by hand manually.

\section{B. Significance of Study}

The basic question for this study is why does freehand drawing are recognized to be increasingly needed in the world of architectural educations amid the challenges of current technological developments. This study will contribute a transformation criticism of how freehand drawing activities effectively develop architectural sensibility, from the observing, learning, and imaging of thinking. From freehand drawing, hopefully, can also increase the awareness about architectural and design repertoire in whole.

The aim of this research is to examine how the values of freehand drawing skill both in observing and imaging types, which is the cognitive ability (sketching, learning and synthesizing framework) are manifested into the architectural design process. By understanding the importance of freehand drawing skill, we can develop a systematic method of freehand drawing practices, in developing the ability of design thinking in term of part of the architecture design process.

\section{DRAWING In ARCHITECTURE HiSTORY}

\section{A. Early Situations}

Humans used drawing as a way of expressing their existence. The earliest known date of this expression is from 10,000 B.C., where the drawings were found on the walls of caves in France. This was also founded in Spain, India, Portugal, China, Australia even in Celebes in Indonesia. It showed how drawing activities had been established as a part of humankind. The sketches and paintings produced by these Neolithic times were eventually stylized and simplified into symbol systems (proto-writing) and eventually into early writing systems. These drawings, known as pictograms, depicted objects, and abstract concepts.

\section{B. Medieval and Islamic Era}

During the Middle Ages, generally drawings were used in the preparatory stages of a work of art. Drawing was used as a tool for the study of nature, which was becoming increasingly important, and often made a very detailed 
working drawing before beginning to paint. Shading was introduced to suggest solids and textures.

In Islamic tradition, geometric ornaments which are spread in whole of Islamic art, was not drawn by freehand drawing. It was designed with the help of a number of geometric methods which were not always exact, but which allowed the generation of a series of variants. Ottoman architecture is considered as an expression of the renaissance of Islamic architecture. Ottoman architecture was believed develop special methods in term of architectural practices.

Generally, Ottoman used plan and models in design and construction building process. The plans also used to communicate and disseminated of design thinking process. It is clear that from written sources that in keeping with earlier Islamic traditions, Ottoman architecture training included a strong background in geometry. This principle will be explored with plan and models. But practically Ottoman emphasis on volume rather than form, and subordinations of decorations to structure also reflected an aesthetic preference in which quality and structure strength were intimately bound. (Necipoglou,1986).

\section{Renaissance Era}

The new era of drawing in Europe began in the 1400s in Italy, during the period known as the Renaissance. Among the most celebrated draftsmen (masters of the drawing) of this period are Michelangelo and Leonardo Da Vinci. At this time drawing came to be considered the foundation for work in all the arts. Art students first trained in drawing before going on to painting, sculpture, or architecture.
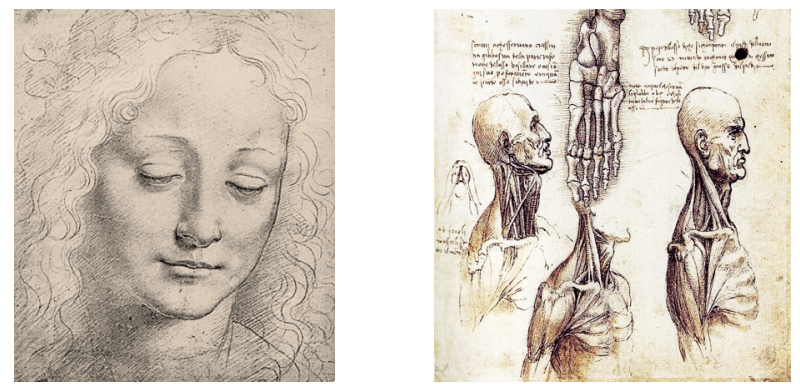

Fig.1. Michelangelo and Da Vinci Sketch's

Da Vinci used dark, sharp lines only to accent and bring depth to the features of the face (the eyes, nose, and mouth). Especially because these accents contrast the softness of the rest of the drawing, they effectively bring our attention to the focal points, that is the features of the face

An important thought from The renaissance period was the use of perspective principles in giving a realistic picture of an object's composition. It's the one of the most powerful moment to make drawing feel more realistic style.

\section{Modern and Post Modern Era}

The development of the drawing then follows the development of the art and industrial movement at that time. For these, architects who share simultaneous periods and overlapping influences, their sketches have both similarities and differences. The Art Nouveau and Secession architects for example, benefited from their close association with graphic and fine artists. They acquired strong sketching skills, which developed from practice, education, and innate talent. Meanwhile, industrialization made such items continually more precise and available, and modern architects need more drawings.

Avar Aalto, an architect who is the sketches most striking one. For Aalto, sketching performed a central function in his creative process, not only in the process of designing, as Aalto himself has spoken of above, but also to train his architectural sensibilities. Alvar Aalto has used sketches for observation and imagination. Capturing various natural phenomena in traveling while using them as a basis for design ideas. Aalto's sketch is very instinctive and expressive (even childlike's composition) by incorporating environmental elements (landscape, sun, etc.). Pallasma calls this character of sketches as a 'The Thinking Hand' [11].

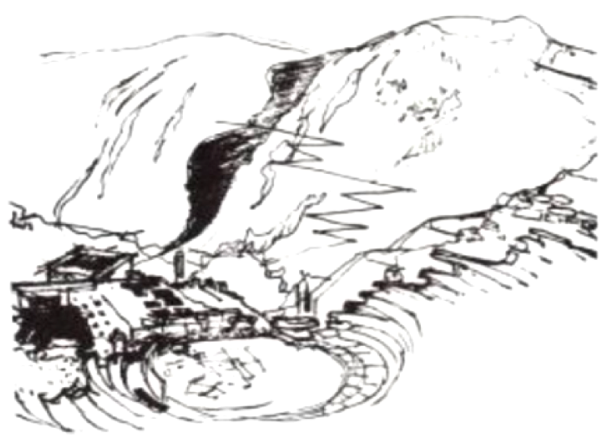

Fig.2. Aalto Sketch's for Delphi, Greece,1958, in Robert 2017

Renzo Piano say about the freehand drawing he made: "I do sketches like that which are midway between writing and sketching. It is a way to remind myself of certain elements of space or a detail. I move very often from a general statement on the relationship of a building to land etc., to small details about a piece. So, what we get is nuts and bolts but also a general concept. These sketches are a way of revisiting the idea by working with the mind and the sketch all the time. [7]"“

Related to paradigm of design thinking, the development of drawing as a discursive practice is a revelation that, like post-modernism itself, is a response to disillusionment with the achievements of the Modern Movement. Outdated sociological criticism - developed outside the architectural discipline - has been replaced by criticism that attempts to return to architecture itself by means of graphic representation.

In the nineteen-eighties the functional and rational sides of representation were increasingly reinforced by poetic and irrational characteristics. No longer is mere information offered to the attentive observer, the drawing presents itself to the imagination as material for play. The drawing is now to be understood as a kind of object for meditation, which transfers perceptual postures, sensibilities and ideas instead of 'thing'. 


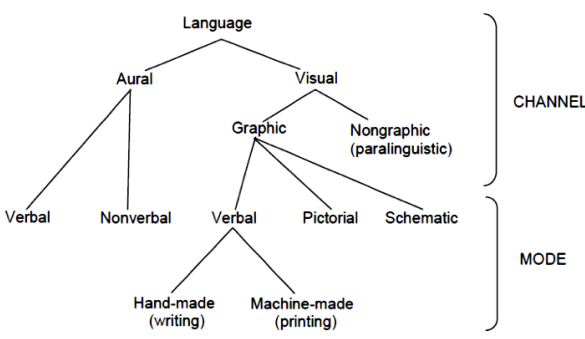
he observes, is more than "the shadow of an object." Architectural drawing attempts to erase absolute objectivity but while doing so also refuses to enter into a dialogue with meaning that admits multiple answers and question

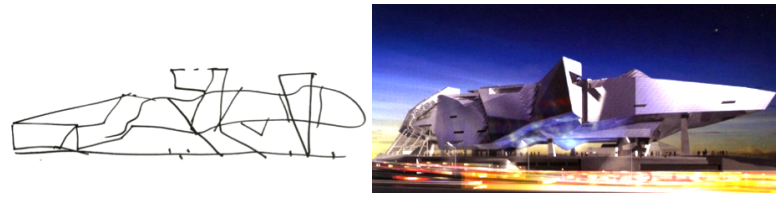

Fig.3. Libeskind sketch's and Building after [7].

\section{E. Drawing And Digital Technology}

It is very interesting to discuss how the relationship between freehand drawing activity and technological developments. Fortunately, thanks to the development of computer tablet technology, freehand drawing especially at sketches expression are now increasingly popular. The benefit of using this technology is, firstly there is so many application in the digital or online market, and secondly designer can share their digital ideas quickly with others, and further this digital sketch can be imported into other software, to become the starting point for other work within the design process [10].

Behind the phenomenon of the considerable benefit of the digital technology, especially in terms of the effectiveness of design productions, it is realized that from the social and health side, the use of technology has an impact on teamwork culture, creative thinking process and the health of neurobrain systems and body.

'In my view, [...] computer imaging tends to flatten our magnificent multi-sensory and synchronic capacity of imagination by turning the design process into a passive visual manipulation, a retinal survey. The computer creates a distance between the maker and the object [11].

\section{EPISTEMOLOGY OF DRAWING}

The word 'drawing' presents a general term, whereas 'sketching' focuses on a specific technique. Both can take the form of an action or object, verb or noun, as each can imply movement.

\section{A. Drawing And Visual Communication}

Visual communication is the most influential media for society. To communicate their thinking, designers mostly use visual graphic elements such as schematic and pictorial (sketches, drawing or photo) as main tools. Together with verbal (writing or printing), the design will be perceived as comprehensive thinking idea.

Fig.4 . Language model: Graphic as Tools of Communications, [6]

Drawings are graphic representation analogously related to the built world through a corporeal dimension and embodying in themselves the chiasm of conceiving and constructing. Drawings cannot be considered as any text at all, only an attempt to talk directly to the production of the building.

\section{B. Drawing And Cognitive System}

In terms of the relationship between drawing and cognitive system, it is important to understand that with drawing activities, we are thinking or learning deeply of an object. If learning is about changing the way we see something, and sketching is a means by which we come to see, then sketching can be seen to be closely associated with learning. Indeed, it could be suggested that when architects use their sketching as a way of coming to see something in a new way as they do frequently when designing, they are using their sketching as a means of learning. With drawing, people will appreciate the place they had drew carefully and could make the quality of perception of the place. Drawing or sketching is an expression of experience. From drawing activities, we will perceive deeply and understandable for the phenomenon around us.

To appreciate a place, one has to draw deeply from it. The word 'appreciate' literally means to take into oneself its preciousness, which is the qualities give it its uniqueness. To draw means to pull from, to take from - one draws water from a well for instance, or one draws a conclusion from an ordering or layering of things. To understand the quality of a place one must draw from it in all sorts of ways. One draws from its origins, its history, its patterns, its form, its communities, its inter-connectedness with other places and its precedents. Its sense, or how one feels about it, comes from this drawing upon all its facet [7].

What makes representation a crucial field in the understanding of architecture is the mediated character of representation itself. There is rarely representation of a 'reality,' or even of an idea or a belief. What representations represent is another representation in a chain of signifiers that circulate from one medium to another all the while believing, or letting us believe, that there is a direct referent [20]. 
Furthermore, this book is giving effective methods

the eye and the brain of the architect, are brought together to promote a keener sense of understanding. Drawing is not just representation it helps the architect to think ideas through. By drawing, people will actives the brain comprehensively with all the body sensory and consciousness. A hand is not simply part of the body, but the expression and continuation of a thought which must be captured and conveyed'.

C. Graphic Learning

Drawings are graphic representation analogously related to the built world through a corporeal dimension and embodying in themselves the chiasm of conceiving and constructing. Several resources for graphic learning in architecture were launched by many author or architects. The important and popular authors are Paul Laseau and Francis DK Ching [1], [9]. Their methods were known as clear and effective enough to develop graphics skill.

\section{Paul Laseau Methods}

Paul Laseau proposed a comprehensive approach about the graphic learning by freehand drawing [8]. As tools for basic thinking of architects and designers, he narrates how freehand drawing activity as a graphic skill should be used for generates cognition and used also for explore the effective visual communication. In his book Freehand Sketching : An Introduction, 2004, Laseau provide practical direction how to develop basic skills to freehand sketching by basis understanding of the combination between seeing and thinking, and then make practices using some tips such as grids, frames, and shapes, to create tone, texture and details. Laseau also suggest helpful topics such as useful equipment, observation skills, framing and editing sketches, rendering people, and the important to keep a journal of drawing activities.

Comprehensively Laseau give a highly visual introduction to the notion of drawing as a mode of thinking in his famous book Graphic Thinking for Architects \& Designers. For Laseau, drawing or graphic image is more than a convenient way to communicate idea, but it is an integral part of the creative process that has a profound impact on thinking and problem solving. Laseau also demonstrated that more versatile and facile sketching leads to more creative approaches to design challenges. Laseau start graphic learning by how we have to understand about the basic of graphic skill. He was dividing the skill in four types of basic skills support graphic thinking are:

- Observation

- Perception

- Discrimination

- Imagination

Practicing repeatly freehand drawing significantly will develop the graphic thinking. And by the drawing actions, architect will develop the observation skill, perception skill, how to discrimated and image something. In observation for example, what we see critically, will affect critically the way we think. For this reason, seeing and thinking will develop integrally in freehand drawing, its a principle process in developing creative thinking. For Laseau, drawing or graphic image is more than a convenient way to communicate idea, but it is an integral part of the creative process that has a profound impact on thinking and problem solving.

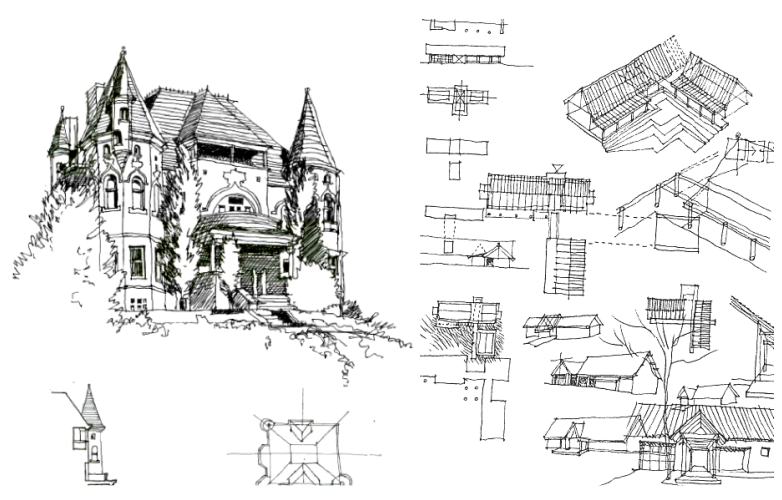

Fig.5. Graphic Learning from Laseau methods

Fig.6. Drawing Representations fom DK Ching

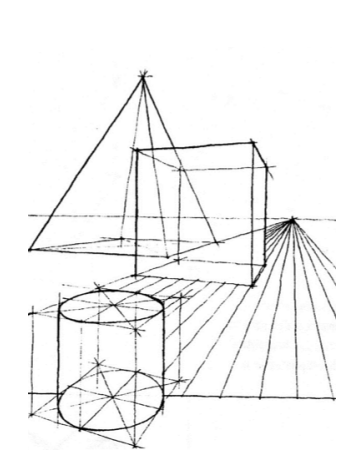

Although reehand
drawing has uniqueness,
originality, sometime very
personal and flexible characteristics, but as a tool for build design language, practice and consistency and drawing technique principles to get the common and right perceptions for architectural design ideas or thought. Because of that, designers should understand about the basic principles of drawing system for building spaces representations, such as site plan, elevation, section, perspective, parallel projections and some guidance for technical principles.

\section{Francis DK Ching Methods}

Francis DK Ching is one of the famous architects who concerned with freehand drawing learning. Basically, Ching dividing drawing techniques in 2 categories, drawing from observation and from imagination. the main emphasis of freehand drawing activities is to produce drawing system. Ching presents a systematic understanding of architecture by how the spaces will forming by its basic elements, form and shapes. By his careful and neat lines and scratches, he is arranging these basic elements in creating the organizations of spaces, the basic principles of architectural repertoar. Furthermore, little bit technically, he is also explaining the principle of circulations and the principles of ordering systems.

Ching begins the freehand drawing description and practices by understanding the importance of the lines through many examples and exercises. He said that the line is the soul of the drawing. Because of that, many kind of lines exercise on his book. The consistency of the line intention is very important to produce the form or image. By the lines, it can be explore much basic geometric or natural organic shapes, formal or informal images expressions, focus or peripheral atmosphere perceptions.

After lines practicing, Ching continued drawing practices with shading exercises to explore the tone and texture of the images. Then by freehand drawing he develops 
alternatives sketches for masses composition, define the initial or basic idea, continue the process to development design and final presentation step. While Ching is mainly in the effort to produce comprehensive drawing system and graphic composition of presentation techniques.

In creative design activities, there are iterative process, which is generally will be conveyed by graphic cyclic feedback. Every step of process possibly needed different character of graphics expression. The notion of graphic thinking grew out of the recognition that sketching or drawing can support the designer's thinking. The graphic image and thinking are one, a unity. It is a faculty indispensable for an architect. because it is presented with neat and careful freehand drawings. Laseau started the explanation from a basic philosophical point of view, the importance of freehand drawing activities as a basis for designers thinking, by observation, perception and imagination drawing practises. While Ching view drawing as a representation technique of an object, by observation, imagination and presentation drawing practices. The expressions and characters of the lines from Laseau are slightly free and flowing, while the Ching lines are more straightforward, orderly and consistent.

Actually, both of Laseau and Ching approaches are needed and complementary in generating architecture repertoire awareness and increasing ability in freehand drawing skill. This method can be combined and is still very significant to use, and certainly needs to be developed while maintaining personal character of freehand drawing, and most important is these methods provide opportunities for the emergence of creative ideas in design process.

\section{DRAWING AND DESIGN PROCEESS}

The situation of the process in design is very specific. There is no right way to design [10]. Principally, the design is problem-solving and iterative process, because continues cyclical and does not happen once. The building or built environment design in contemporary situations nowadays is also a service activity, because architects should provide design communication and respons for a design need. One of the best methods of managing conflict, efficiency, and aesthetics in today's building design challenge is offering graphic thinking tools along with the design process. As a way of communications, the graphic image is an integral part of the architectural design process, from the initial observing, inventory of site data, identification of a design problem, evaluation and analysis, exploring the concepts and preliminary design, elaborating the development design, until refinement the technical and details of architectural drawing.

There are several models in design process. RIBA have "Plan of Work" which is all the process was organized in 7 stages, while AIA have "The Five Phase of Design ". Design Council in UK have "The Double Diamond "of the design process model. Basically, all the model of design process divided in Preparing step of design, Conceptual Design, Developmen Design and Technical Design. In each step of these stage of design process, freehand drawing still has an important and significant role.

Paul Laseau elaborated the role of freehand drawing very well in each step of design process, especially in preparation step to search and identification design problem, make graphics for site, form and functional analysis, explore the
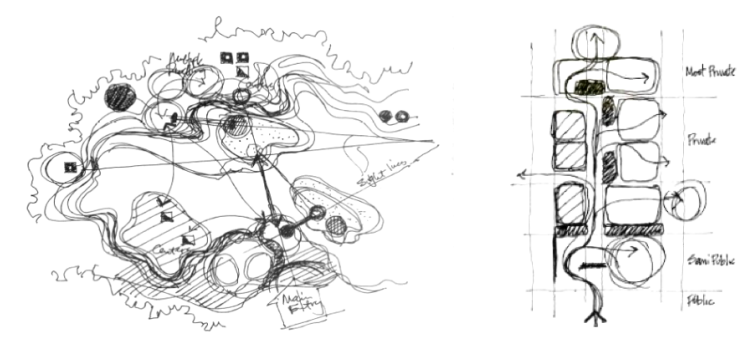

Fig.7 . Drawing in site analysis and zoning concept process

able to reveal things unforeseen or previously unintended. The graphic image is fundamental in developing imagination, which is the basic aspects of creative thinking for the architectural design process.

\section{OBSERVING AND IMAGINING IN FREEHAND DRAWING}

Since the beginning of human civilization, images have been used as a medium for expressing thoughts, especially expressions of the existence of society and respect of believe The use of images as part of observational thought, developed after the Middle Ages, both in Islamic culture and also in eastern cultures and its peak during the Renaissance, when humans developed visual records in recording and studying a natural phenomenon around, and developed it as a foundation of scientific thought. After that time, in the early days of modern architecture, hand drawing activities were the best method of studying, honing and developing an architectural repertoire or grammar for an architect, and this had a powerful influence on subsequent thinking.

Thomas Jefferson, Aavar Alto and Frank Lyoid Wright made a travelling for architectural pilgrims (observational drawing activities) to Greece, Italy and France, while Le Corbusier toured the Mediterranean and visited Greece, Italy and especially Turkey, as part of the way for their deepness and sharpness in architectural thinking. Interestingly, they are all did very unique, have character and loose observation sketches. As stated in the previous paragraph, sketching is an architect's way of understanding and offering a design idea, which is a special and personal.

While Alto's sketch is child'slike compositions, Le Corbusier sketch's relatively more organic and very expressive, with bolder lines and strokes. Eventhough theses systems. So the picture is used more than as a thoughtful idea. 
look like expresionism character, both of them still always try to show architectural principle thinking, such as how building or city elements (landscape, sun, trees ) will be experienced and perceived as basic character of spaces understanding, or an expression of spaces experience.

Le Corbusier, in some sketch's, was discriminate some elements of the objects to show other importance thing. It is the basic thinking of observation sketch's. To show the basic design idea, which is define the principle of order (scale, proportion, unity with sorroundings, rythm of detils), it is no need to draw the gates in the front of the mosque. This ability need many practices.

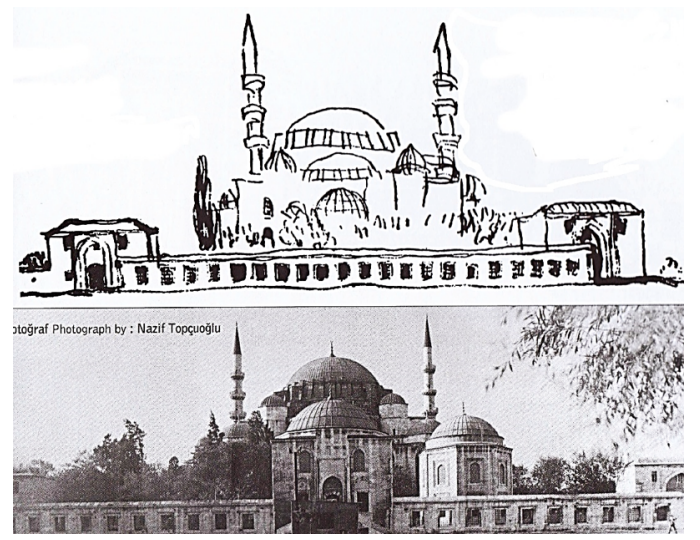

Fig.8. Discriminating observation sketchs, Le Corbusier.

In imagining sketchs, freehand drawing has the advantage of quickly and easily a design idea to be visualized. With freehand drawing, architectural design seems had an unique and strong of the designer's energy, which is needed to kept until the development of design process. Alto was use sketch's in site analysis to imagine the opportunity of design, while Libeskind is explor the opportunity of freehand drawing to reach beyond the limitation of lines, where generally only used to be as a border of building form ad shapes.

In the digital era, various methods of graphic visualization in the design process are also develop. Besides who persist with the orthodox method, which is using traditional media such as paper and drawing tools, now also developing the methods which is replacing traditional media with digital media, but it is still relatively similar drawing process. with hybrid solutions, some using manuals, some using digital. Or what is currently a challenge is the process of fully digital drawing is a virtual visual language, which starts from the initial exploration completely free of traditional architectural vocabulary.

Generally, digital image exploration is more widely used for the process of imagination in design ideas. Visually the architectural expression of a digital image will give a very impressive impression, because it uses a more precise algorithmic program, supported by a choice of technical finishes and a very rich material source or embedded library. But most architecture educators or designers are complained about the lack of consciousness, awareness and understanding of the design process. Technically, it is very difficult to do graphic activities in the field using digital image media. This gap in starting observations is likely to be a missing part of the designer's cognitive quality in mastering architectural values in a design process.

\section{IV.CONCLUSIONS}

Designing is still remaining a creative process that must originate from a comprehensive understanding that involves consciousness and imagination. The basic expression of architectural design thinking will always the same, presenting ideas of aesthetic principles that can be understood as well as the principles of spatial systems that can be calculated. As part of the way of communicating with the public in modern times, where scale and building systems are becoming more complex, architectural drawings are also required to be responsive to accommodate the development of design technology that is developing rapidly in today's digital world.

According to description above, it is very clear that drawing not just an illustration, but the way of expression of architectural thinking. Graphically, the importance of freehand drawing activities can be seen in the following scheme:

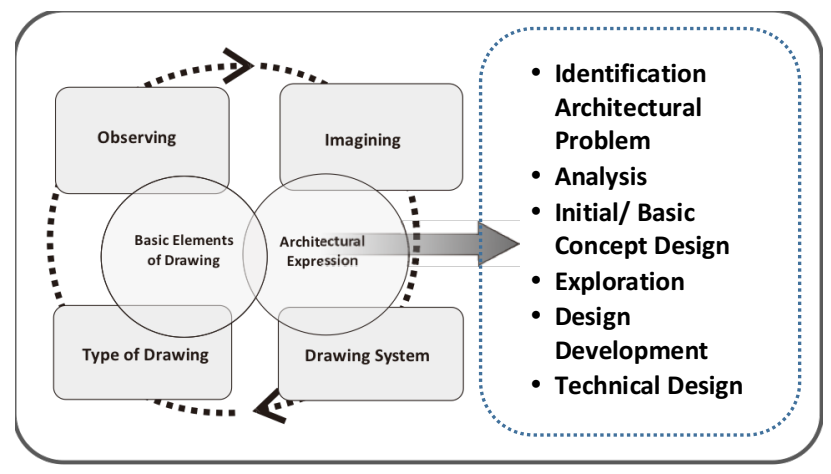

Fig.9. Observing and Imagining Drawing Process, Budiman 2019

Drawing activities can guide architects to an understanding of architecture as both constructed and construed. The other important is, by the drawing, it will show the whole process of architectural design thinking. Bright thinking is always supported by a depht and complete reading, and inspiring graphic images or drawing is certainly supported by deep observations.

\section{ACKNOWLEDGMENT}

The author is grateful to Prof Ibrahim Numan at Department of Architecture, Faculty of Architecture and Design, Fatih Sultan Mehmet Vakif University, Istanbul, for his supervisor and advises about Freehand Drawing and Design Thinking, discussion and generous advise along writing this paper.

\section{REFERENCES}

[1] Ching, Francis DK, Architectural Graphics, John Wiley and Sons, New York, 2009

[2] Ching, Francis DK, Design Drawing, John Wiley and Sons, New York, 1998

[3] Duff, Leo and Davies Jo, Drawing The Process, Intelect Books, Oregon, 2005

[4] Edward, Bran, Understanding Architecture Thorugh Drawing, Taylor \& Francs, Oxon, 2008

[5] Joannides Paul, The Drawings of Michelangelo and His Followers in the Ashmolean Museum, Cambridge University Press, New York, 2007 
[14] Katrowitz, Andrea, Thinking Through Drawing : Practice Into Knowledge, Proceedings of an interdisciplinary symposium on drawing, cognition and education, Columbia University, New York, 2011

[15] Pilsitz, Martin, Drawing and Drafting in Architecture Architectural History as a Part of Future Studies, Researchgate Journal, 2017

[16] Pilsitz, Martin, Drawing and Drafting in Architecture Architectural History as a Part of Future Studies, Researchgate Journal, 2017

[17] Shalem, Avinoam, What do we mean when we say 'Islamic art' ? A plea for a critical rewriting of the history of the arts of Islam, Muenchen, 2014

[18] Sera, Juan, Forget What You Have Learned: Spontaneous Drawing For The Genesis Of Architecture, Procedia - Social and Behavioral Sciences 191 ( 2015 ) 1128 - 1134, 2014

[19] Makela, Drawing as a Research Tool: Making and understanding in art and design practice

[20] Wood Peter, Drawing The Line : A Working Epistemology For The Study Od Architectural Drawing, Doctor of Philosophy in Architecture, The University of Auckland, 2002 